\title{
AVALIAÇÃO DE LÍNGUA INGLESA: RUPTURAS E PERSPECTIVAS
}

\author{
Cristina Arcuri Eluf* \\ Fabio Nascimento Sandes ${ }^{* *}$
}

\begin{abstract}
Resumo: O presente artigo envolve questões acerca da avaliação da aprendizagem de Língua Inglesa perante as demandas da nova economia (KALANTZIS et al, 2003). O trabalho discute propostas de práticas avaliativas como alternativas para se pensar o processo de ensino/aprendizagem em Língua Inglesa no atual contexto global. Nesse caso, analisamos uma avaliação prática, baseada na Pedagogia dos Multiletramentos (NLG, 1996), a qual foi experienciada por graduandos do penúltimo semestre do Curso de Formação em Letras Modernas da UESB. O corpus da pesquisa foi construído pelos alunos como critério avaliativo da disciplina Introdução à Linguística Aplicada a fim de testar sua exequibilidade em sala de aula durante o pré-serviço.

Palavras-chave: Avaliação. Contexto global. Linguística Aplicada Crítica (LAC).
\end{abstract}

\begin{abstract}
This paper focuses on issues concerning the English language assessment in the light of New Economy demands (KALANTZIS et al, 2003). It also portrays some suggestions for evaluation practices as alternatives to ponder the process of English teaching and learning within the current global context. On this paper, a practical assessment has been analyzed, based on the Multiliteracies Pedagogy (NLG, 1996), which was experienced by seniors from the Language graduation course at Universidade Estadual do Sudoeste da Bahia. The corpus was collected by the students as an evaluative criterion for the class "Introduction to Applied Linguistics" so as to find its feasibility along their pre-service.
\end{abstract}

Keywords: Assessment. Global context. Critical Applied Linguistics (CAL).

\section{Introdução}

O texto a seguir é fruto do amadurecimento de uma inquietação que há muito vem alterando nossa formação e postura enquanto linguistas aplicados: a avaliação da aprendizagem de língua inglesa.

Se fizermos um levantamento bibliográfico, constataremos que a literatura nessa área ainda é incipiente. Uma investigação realizada por Quevedo-Camargo (2011, p. 476), por exemplo, sinaliza a escassez de trabalhos referentes ao assunto, o que ratifica o panorama apresentado por Moita Lopes (1999) sobre os tópicos de pesquisa mais prestigiados no Brasil nas décadas de 1970, 1980 e 1990. O tema "avaliação" (escolar, curricular, institucional ou mesmo docente) não consta na lista.

Quevedo Camargo (2011), respaldada em Scaramucci (2006), confere que, se fizermos um exame dos currículos de formação de professores de línguas (materna ou estrangeira), evidenciaremos a inexistência de preocupação com questões relativas à avaliação. A autora advoga que os professores formadores devem, consistentemente, trabalhar as questões relativas à avaliação durante a formação inicial e continuada do professor em formação.

Com vistas a melhor elucidar essa questão, a busca por responsabilidade e mensuração tem alcançado dimensões globais em termos de produção de resultados educacionais. Isso ocorre em função de interesses de aprendizes individuais, que se

\footnotetext{
"UESB - Universidade Estadual do Sudoeste da Bahia; Professora Adjunto/PPGCEL - Programa de Pósgraduação em Letras: Cultura, Educação e Linguagens; Vitória da Conquista; Bahia; Brasil; E-mail: criseluf@gmail.com

${ }^{* *}$ UESB - Universidade Estadual do Sudoeste da Bahia; Mestrando/PPGCEL - Programa de Pós-graduação em Letras: Cultura, Educação e Linguagens; Vitória da Conquista; Bahia; Brasil; E-mail: fnsandes@ gmail.com
} 
beneficiam de uma cultura de competição e do acréscimo de conhecimento voltado as suas preferências individuais (KALANTZIS et al, 2003, p. 15).

Assim, tomando como parâmetro nossa formação escolar e a prática frequente de avaliações padronizadas, não relacionadas a contextos reais (BRASIL, 2002, p. 9), como podemos melhor preparar professores em pré-serviço para desenvolver uma proposta avaliativa de ação, tendo em vista as habilidades e os atributos exigidos pela nova ordem mundial? A alternativa proposta será discutida a seguir.

\section{Por uma reinvenção das formas de avaliar}

A avaliação é tradicionalmente associada, na escola, à criação de hierarquias de excelência. Os alunos são comparados e, em seguida, classificados em virtude de uma norma de excelência, definida no absoluto ou encarnada pelo professor e pelos melhores alunos (PERRENOUD, 1999).

Uma retrospectiva na história da escola nos remete à lembrança de que avaliar é criar hierarquias de excelência, em função das quais se decidirão a progressão no curso seguido, a orientação para diversos tipos de estudos, a certificação antes da entrada no mercado de trabalho. Segundo Perrenoud (1999), avaliar é também privilegiar um modo de estar em aula e no mundo, valorizar formas e normas de excelência, definir um aluno modelo, aplicado e dócil para uns, imaginativo e autônomo para outros.

Como é possível observar, avaliar não é uma tarefa fácil, uma vez que, ao avaliar, o avaliador não se desvencilha de suas preferências, subjetividades, normas e valores. Ao eleger um aluno como modelo, por exemplo, como aquele que alcança a maior nota dentro da lógica de aplicação de um mesmo teste para alunos com diferentes níveis de aprendizagem e conhecimentos de mundo, o avaliador o equipara dentro de uma escala de atribuição padronizada de notas, o que é, no mínimo, perverso, por se tratar de uma prática que é a tradução do que Perrenoud (1999) denomina 'criação de hierarquias de excelência'.

Duboc (2004) aponta que, no paradigma moderno (sociedades essencialmente tipográficas), o sujeito produzia conhecimento de forma centralizada, concentrada, individual, privada e ainda baseando-se em normas pré-estabelecidas. Já o sujeito da atual sociedade póstipográfica (inscrita, portanto, na pós-modernidade), distribui e compartilha saberes, segundo a autora (2014), dentro de uma lógica muito mais colaborativa e pública, partindo da experiência na ausência de modelos padronizados e previamente estabelecidos.

No entanto, uma contradição incide na prática. Embora os sujeitos da sociedade póstipográfica estejam habituados com o compartilhamento dos saberes, dentro de uma lógica muito mais veloz e colaborativa, a escola, por outro lado, ainda provê seus alunos, muitas vezes, com modelos padronizados e previamente estabelecidos.

Conforme aponta Stuart Hall, a sociedade moderna apresenta abalos dos "quadros de referência que dão aos indivíduos uma ancoragem estável no mundo social" (HALL, 2006, p. 7). Essa relevante alteração de paradigmas é o primeiro fator a ser levado em consideração se quisermos propor uma redefinição do currículo escolar. Por redefinição do currículo escolar, entende-se:

a inserção de atividades que visem à formação de alunos sensíveis à diversidade linguístico-cultural e conscientes da heterogeneidade nos usos da linguagem, num exercício que ensina aspectos linguísticos e ainda amplia a perspectiva do aluno sobre questões como sociedade, cultura, linguagem, cidadania, identidade, raça, gênero (DUBOC, 2014, p. 6). 
Esse exercício de expansão de perspectivas (MONTE MÓR, 2008, 2010, 2011 apud DUBOC, 2014) possibilitaria, segundo Duboc (2014), a formação de cidadãos críticos e éticos, portanto, propensos a melhor lidar com a diferença e a complexidade das sociedades pós-modernas. Desse exercício de expansão de perspectivas depreende-se que, ao invés de reproduzir formas linguísticas previstas, o sujeito passa a ter a oportunidade de responder ao seu entorno, reconhecendo a heterogeneidade não só nos usos da língua, mas também na produção de sentidos (DUBOC, 2014), pois, como sugere Perrenoud (1999, p. 10), em torno da norma e das hierarquias de excelência, nenhuma sociedade vive na serenidade e no consenso.

Assim, essa proposta apresenta uma relação muito próxima com o tripé que constitui a universidade, ensino e a pesquisa e extensão, pois a partir da formação integral engajada com a promoção de cidadãos críticos, o sujeito-aluno tem a oportunidade de enxergar para além do pré-estabelecido, criando outras possibilidades e cambiando sentidos de forma mais crítica e colaborativa em seu entorno.

Nesse aspecto, Perrenoud (1999) relembra que, desde que a escola existe, pedagogos se revoltam contra as notas e querem colocar a avaliação mais a serviço do aluno do que do sistema. Conforme destaca Duboc (2014), os debates em voga reiteram a necessidade de questionar os propósitos da avaliação, recuperando o teor subjetivo inerente à ideia de avaliação, em vez de seu entendimento como mero sinônimo de medida.

Diante das circunstâncias, a avaliação passa a ser entendida como prática processual, formativa, subjetiva e variada, não mais a serviço da exclusão, mas sim, do desenvolvimento cognitivo e afetivo do aluno (DUBOC, 2014). Eis que uma nova lógica se impõe, no interior de um dispositivo de pedagogia diferenciada (PERRENOUD, 1999, p. 11), como um fenômeno merecedor de múltiplos tratamentos (LUCKESI, 2000, p. 12).

Essa lógica diferenciada, a que se refere Perrenoud (1999), desempenha uma função pedagógica extremamente importante, pois tal lógica, inserida em um dispositivo como um fenômeno merecedor de múltiplos tratamentos oferece ao sujeito-aluno mais oportunidades para criar novas relações diante do conhecimento, fazendo-o sentir mais confortável, na medida em que ele deixa de ser um mero reprodutor de conhecimento para ser co-produtor do que fora proposto a ele.

Nesse sentido, essa nova lógica dialoga com os pressupostos da definição do que vem a ser "ensinar" para o linguista Prabhu (2003), o qual afirma que ensinar é esperar que o melhor aconteça. Segundo o autor, não há como determinar com precisão como a aprendizagem ocorre em todos os alunos, por conta da imprevisibilidade e, ao mesmo tempo, intangibilidade de seu processo em cada aluno. Por isso, concordamos com Duboc (2014), na perspectiva de que é lícito conceber a avaliação como, de fato, prática processual, formativa, subjetiva e principalmente, variada, para que haja mais oportunidades de ocorrência da aprendizagem.

\section{O professor de línguas e a nova ordem mundial: a vez do "ajuste dos relógios"}

Em conformidade com Lankshear e Knobel (2003), diversos elementos estimularam o desenvolvimento das teorias de letramento ao final do século $\mathrm{XX}$, dentre os quais a pedagogia crítica de Paulo Freire, a necessidade de reforma curricular nos Estados Unidos dos anos 60 e a emergência de estudos socioculturais (LANKSHEAR; KNOBEL, 2003, apud DUBOC, 2007).

As implicações desses movimentos culminaram no estabelecimento de uma nova proposta pedagógica no campo educacional, a saber: a quebra do conhecimento pré- 
estabelecido, tradicionalmente imposto pela escola, e o anúncio do conhecimento da era digital, talhado num formato dinâmico, animado e instável. Desse modo, em vez da priorização do conteúdo concentrado e individualista da epistemologia convencional, passa-se a priorizar o conhecimento distribuído, cuja construção torna-se mais pública e menos verticalizada, ecoando o poder de agência dos sujeitos outrora tímido ou até mesmo velado (cf. DUBOC, 2007).

O conceito de conhecimento distribuído apresentado por Gee (2004, apud DUBOC, 2007) contrapõe-se ao conceito de conhecimento postulado pelo velho capitalismo. Ao pressupor sistemas lineares, hierárquicos e autoritários nos quais o conhecimento concentrava-se no ápice da pirâmide, a engrenagem fordista acabou por determinar uma concepção de conhecimento concentrado que se estendeu na esfera escolar ao longo do século (cf. DUBOC, 2007).

Essa tomada de posição dos dirigentes da engrenagem nos remete ao profundo fosso cavado entre o linguista e o leigo, a que se refere Rajagopalan (2010, p. 222). "Linguista e leigo", neste contexto, podem ser interpretados como "professor e aluno", ou ainda testers e test takers (SHOHAMY, 2001, p. 3).

Como esclarece Rajagopalan, a ênfase exagerada na dimensão racional da linguagem é acompanhada de uma quase total negligência do emocional. $\mathrm{O}$ foco na racionalidade, isto é, no conhecimento concentrado, tem significado um movimento simultâneo de relegar as emoções às margens (RAJAGOPALAN, 2010, p. 226).

Vale ressaltar que a emoção é um fator que influencia o estado psíquico e a maneira de pensar e agir dos indivíduos. A esse respeito, Oatley (1999 apud RAJAGOPALAN, 2010) demonstra que grande parte da pesquisa recente sobre emoções tem se concentrado na maneira como as emoções influenciam os processos cognitivos durante os julgamentos e processamento de inferências. Logo, as emoções, a bagagem e prerrogativas de mundo dos alunos devem ser levados em consideração no que concerne à avaliação. Revisitando os ensinamentos freireanos, Rajagopalan $(2010$, p. 240) nos chama a atenção para a lição que Freire legou para a posteridade:

A única maneira de ser bem-sucedido no ensino é dialogar com nossos alunos a partir de onde estão e não esperando que, através da exposição repetida do nosso discurso racional, eles sejam arrebanhados para nosso lado, passando a enxergar a racionalidade de nossos argumentos.

Dessa maneira, faz-se necessário, segundo Rajagopalan (2010), entender o locus de enunciação do outro, para se entender as novas lógicas. Por isso, fica patente quando Kalantzis et al (2003) nos dizem que qualquer que seja a justificativa de uso de uma avaliação padronizada, universal e regular, sua função de medir as habilidades e sensibilidades requeridas no atual século é limitada e tende a falhar.

Segundo Perrenoud (1999), a avaliação tem a função, quando se dirige aos examinadores, de criar variações que se referem mais à escala e ao princípio da classificação do que às variações significativas entre os conhecimentos dos examinandos.

Diante desse ponto de vista, Kalantzis et al, (2003) propõem uma ampla gama de estratégias avaliativas que focalizam a performance de tarefas, o planejamento de realização de projetos, trabalhos em grupo, bem como a apresentação de portfólios, os quais, na opinião dos autores, refletiriam melhor as habilidades em foco.

Como discute Moita Lopes (2003), o indivíduo no mundo do trabalho contemporâneo passa a ser visto como um portfólio (Gee, 2000b) que dispõe de habilidades e competências variadas, ou múltiplas habilidades, segundo Luke (1997).-Conforme Kalantzis 
et al (2003), a busca e a implementação de estratégias avaliativas mais diversas reduziriam a quantidade substancial de tempo e dinheiro gastos em práticas míopes e ultrapassadas de testes padronizados.

Moita Lopes (2003), em seu artigo A Nova Ordem Mundial, os Parâmetros Curriculares Nacionais e o Ensino de inglês no Brasil: a base intelectual para uma ação política, afirma que:

se a educação quer fazer pensar ou talvez pensar para transformar o mundo de modo a se poder agir politicamente, é crucial que todo professor - e, na verdade, todo cidadão - entenda o mundo em que vive e, portanto, os processos sociais, políticos, econômicos, tecnológicos e culturais que estamos vivenciando. Não se pode transformar o que não se entende. Sem a compreensão do que se vive não há vida política. E é aqui, que podemos dar nossa maior colaboração, em virtude do material com que trabalharmos: os discursos construídos em inglês (MOITA LOPES, 2003, p. 27).

Moita Lopes (2003) observa que é através dos discursos construídos em inglês que nós professores podemos dar a nossa maior colaboração em direção à transformação do mundo, de modo a se poder agir politicamente.

Para o pesquisador Gee (1994) há uma especificidade em relação a professores de línguas, pois, ao trabalharem com a linguagem, estão centralmente envolvidos com a vida política e social. Nessa esteira, Moita Lopes (2003) indica que os professores de inglês estão no âmago dos temas educacionais culturais e políticos mais cruciais de nossos tempos gostem ou não. Conforme o autor, a educação linguística está no centro da vida contemporânea, porque o discurso ocupa um papel preponderante na vida social hoje em dia.

Ecoando Santos (2000, p. 74), vivemos em "um mundo no qual nada de importante se faz sem discurso". Assim, deve ser considerado, também, o perigo do discurso único, segundo Moita Lopes (2003), o discurso global "que atravessa o mundo em tempo real, tornando as massas mais facilmente manipuláveis" (MOITA LOPES, 2003, p. 30).

No tocante aos processos de avaliação e de averiguação das performances de práticas em ensino de inglês, Brydon (2010) afirma que nossas pesquisas estão cada vez mais centradas no aprendizado do aluno e na diversificação crescente, frutos que também provêm de discursos globalizadores da nova ordem mundial, principalmente quando a questão é privilegiar ações baseadas no uso de tecnologias, em contrapartida daquelas ações realizadas vis-à-vis, na sala de aula (BRYDON, 2010).

Moita Lopes (2008) salienta a pertinência do professor de inglês em se preocupar com aspectos sociopolíticos relativos ao mundo em que vive e ressalta a relevância de o professor de línguas, notadamente o de inglês, tomar consciência do mundo em que está situado e afirma que ninguém transforma aquilo que não pode compreender. Nesse sentido, enquanto não entendermos o problema, não haverá solução. Por isso, a avaliação exerce um fator preponderante nesse ensino, porque é sua parte constitutiva.

Segundo Santos, essa atual ordem mundial, que atravessa o planeta em discursos majoritários é regida por "acelerações", isto é, momentos culminantes na história, como se abrigassem forças concentradas, explodindo para criarem o novo. A marcha do tempo, segundo o autor (1994), é marcada por grandes perturbações, aparentemente sem sentido, e que geram reações de admiração ou de medo diante do inusitado e da dificuldade para entender novos esquemas e para encontrar um novo sistema de conceitos que expressem a nova ordem da gestação (cf. SANTOS, 1994).

$\mathrm{Na}$ busca por um sentido, o sociólogo descreve que, ao contrário das verticalidades, regidas por um relógio único, implacável, nas horizontalidades, ou melhor, nas distribuições 
do conhecimento, funcionam vários relógios, realizando-se paralelamente, várias temporalidades (cf. SANTOS, 2001). Foi nessa perspectiva que tentamos explicitar, através desse texto, intitulado Avaliação da aprendizagem de língua inglesa: rupturas e perspectivas, o rompimento com a pressuposição dos sistemas lineares, hierárquicos e autoritários. Buscamos ampliar a questão da prática avaliativa em prol de seu reenquadramento ou recategorização para uma pedagogia voltada para múltiplos tratamentos e diversas frentes de trabalho ao invés de práticas engessadas, verticalizadas e monolíticas.

\section{Propostas alternativas para práticas avaliativas de LI à luz da LAC}

De acordo com Celani (2008, p. 18), "mudanças quase sempre encontram barreiras na inércia, na ignorância e na incerteza inibidora" e que ocorre, ainda, a questão do poder e da influência: aquele com sua base na autoridade e este com sua base na confiança e no respeito mútuo.

Para a autora (2008, p. 18), no cenário da educação linguística no Brasil, a "complexidade é grande, as dificuldades são muitas, mas a questão deve ser enfrentada". Todo processo de elaboração de diferentes práticas e políticas vinculadas à educação em nosso país, devem considerar que

um processo de elaboração de uma política educacional eficaz consiste na fixação de uma série de objetivos, enunciados em termos concretos e práticos, que devem servir de guia para a ação imediata contendo mecanismos de avaliação. As medidas concretas de como se atingir as metas devem estar claramente explicitadas. Além do mais, os objetivos devem ter relevância para os sujeitos envolvidos e devem ser colocados em escalas de prioridades; por exemplo, garantir um ensino de qualidade em oposição a construir mais escolas. Para determinados políticos, a prioridade em relação à oposição citada como exemplo seria clara uma vez que a escola construída, ou até em construção, tem maior visibilidade do que a qualidade de ensino, podendo, assim, carrear votos mais facilmente (CELANI, 2008, p. 18).

Para Celani (2008, p. 18), na implantação de qualquer "nova" política educacional o "conhecimento dos especialistas não basta: as ações da comunidade é que são importantes" e mecanismos de consulta devem ser estabelecidos, para que se tenham a opinião de importantes setores daquela comunidade. O trabalho com a linguagem na escola é fundamental, já que é lá que se está preparando os indivíduos para sua atuação como cidadãos com plena capacidade de atualizar seu potencial intelectual e afetivo na força de trabalho e na vida social como indivíduos esclarecidos e eficientes.

Diante disso, Moita Lopes (2008) afirma que, em sala de aula, é central que "atuemos por meio de uma percepção aguçada do momento sócio-histórico em que nos encontramos, para situar nossa prática, e, assim, para situar nossos alunos" (MOITA LOPES, 2008, p. 27).

De tal modo, ao inscrever-se na tradição investigadora e reflexiva da Linguística Aplicada Crítica (LAC), procuramos apresentar alternativas para práxis avaliativas no ensino/aprendizado de LI, sob a ótica dos multiletramentos críticos, em disciplinas de Língua Inglesa e Linguística Aplicada nos cursos de graduação da UESB, campus Vitória da Conquista.

A percepção de disciplinas de Introdução à LA na graduação para professores em pré-serviço respondem à necessidade de vincular nosso trabalho a uma epistemologia e a 
teorizações que "falem ao mundo atual e que questionem uma série de pressupostos que informam uma LA modernista" (MOITA LOPES, 2006, p. 12) como prática problematizadora.

Ao descrever o atual "paradigma da aprendizagem interativa ou colaborativa" sugerida por Lemke, em 1994, Rojo (2010) afirma que hoje o mundo espera que as pessoas professores, cidadãos, dirigentes - saibam guiar sua própria aprendizagem, tenham autonomia e saibam buscar como e o que aprender, que tenham flexibilidade e consigam colaborar com urbanidade (cf. ROJO, 2012, p. 27).

Assim, revisitamos, na disciplina de LA, os movimentos pedagógicos descritos pelo NLG a partir dos pressupostos da pedagogia dos multiletramentos. Para que os alunos pudessem construir, colaborativamente, uma prática avaliativa, partimos das propostas do The How of the Pedagogy, parte do manifesto publicado pelos pesquisadores em New England, em 1996. O NLG apresentava uma proposta que pudesse ser levada a efeito, ao definir essas complexidades das novas práticas educacionais e propor a integração de quatro fatores que amparassem as práticas pedagógicas (ELUF, 2010):

Prática Situada (Situated Practice): experiências de mundo e design dos aprendizes; $\square$ Instrução Aberta (Overt Instruction): definição de uma metalinguagem explícita de design elaborada por aprendizes;

Construção Crítica (Critical Framing): estabelecimento de relações sociais entre o significado e o contexto;

Prática de Transferência (Transformed Practice): transferência e recriação de significados de design de um contexto para outro (tal recriação também é desenvolvida pelos próprios aprendizes e pode ser entendida como recepção, produção/distribuição ou redesign).

Estes mesmos fatores passaram por uma atualização durante os últimos dez anos, evidenciada nos trabalhos dos membros do New London Group e de outros colaboradores (COPE; KALANTZIS, 2009).

As orientações pedagógicas na formulação de 1996 adquiriram o status de 'processos de conhecimento ${ }^{2}$ na reformulação de 2006, levando em consideração aspectos dentre os quais: 'experienciando o dado e o novo, 3 , 'conceituando teoricamente"', 'analisando funcional e criticamente' $\mathrm{e}^{5}$ 'aplicando apropriada e criativamente' .

A atualização do trabalho "aprendendo através de designs" envolveu e envolve alunos e professores na medida em que produz textos multimodais dinâmicos e animados, voltados para suas comunidades e experiências de vida, ao mesmo tempo que ampliam seus repertórios comunicativos (COPE; KALANTZIS, 2009).

\section{Análise e discussão da práxis avaliativa}

Os graduandos do penúltimo semestre do Curso de Formação em Letras Modernas da UESB experienciaram uma avaliação prática, baseada na Pedagogia dos Multiletramentos (NLG, 1996). O corpus disponibilizado a seguir foi construído pelos próprios alunos como

\footnotetext{
${ }^{2}$ Knowledge processes.

${ }^{3}$ Experiencing the known.

${ }^{4}$ Conceptualizing with theory.

${ }^{5}$ Analysing functionally and critically.

${ }^{6}$ Applying creatively and appropriately.
} 
critério avaliativo da disciplina Introdução à Linguística Aplicada para ser aplicado em sala de aula durante o pré-serviço, como pode ser observado na Fig. 1.

Figura 1: avaliação prática baseada na Pedagogia dos Multiletramentos

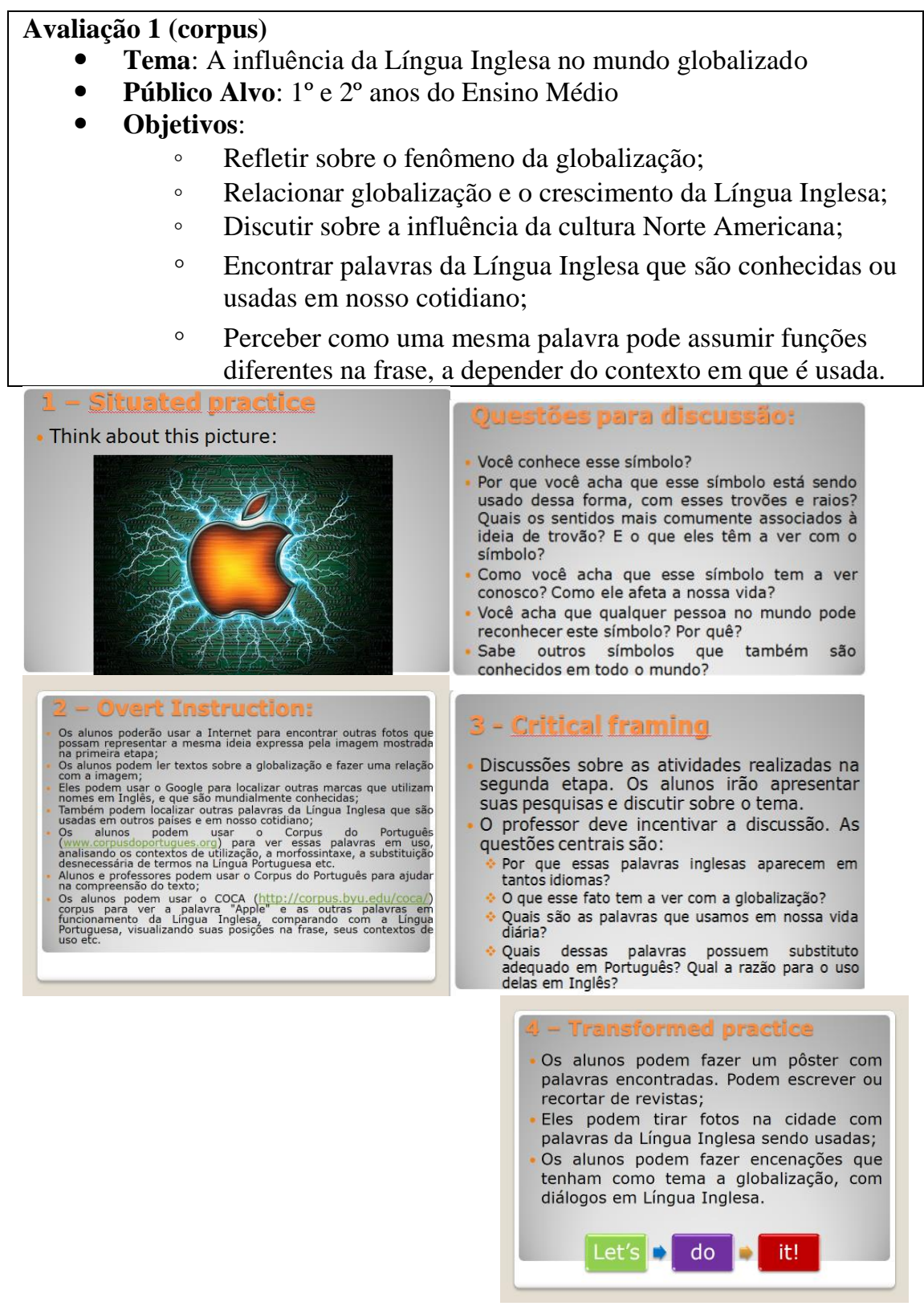

Vale ressaltar que a atividade/prática avaliativa elaborada segundo a proposta das quatro etapas do NLG também se configurou como uma produção "sob pressão", devido à sobrecarga e o acúmulo de atividades pelos quais os alunos têm que passar para obter o título de licenciados.

Nos momentos em que ocorreram os processos avaliativos de ambas as partes, foi possível identificar ressonâncias das teorias trabalhadas durante a disciplina de Introdução à LA, dentre as quais Novos Letramentos, Multiletramentos, Letramento Crítico, e em especial, apontamentos que versaram sobre a "avaliação da aprendizagem de Língua Inglesa" (SHOHAMY, 2001; MCNAMARA, 1996; KALANTZIS et al, 2003; PRABHU, 2003), o que nos autoriza afirmar que tais teorias foram, gradativamente, dando forma ao repertório 
teórico desses professores em formação de modo a contribuir para a futura atuação em suas comunidades.

A maneira como os professores-alunos participaram da (re)construção de suas crenças e o reconhecimento da necessidade de formação na matéria em voga enriqueceram a formação dos professores, sobretudo no tocante não mais da transmissão neutra e passiva de conhecimento produzido por terceiros, mas da construção e revisão de materiais, discursos, práticas e fazeres.

As figuras apresentadas evidenciam o comprometimento e o esforço empreendidos pelos graduandos de, como propõe McNamara (1996), compreender melhor a natureza de seu desempenho e o papel de fomentar as bases para as capacidades de desempenho - próprio e de seus futuros alunos - em contextos de avaliação da aprendizagem de línguas.

Sob o epíteto "a influência da Língua Inglesa no mundo globalizado", os graduandos foram capazes de desenvolver uma avaliação multimodal consoante aos pressupostos da pedagogia dos Multiletramentos.

Diante da avaliação analisada, depreende-se que, tanto alunos quanto professores se percebem desenvolvendo processos de construção de sentidos, de observar-se enquanto construtores e atribuidores de sentidos às coisas.

A prática avaliativa em foco refere-se ao fato de que precisamos permitir sempre alternativas para nossas crenças, possibilidades outras para nossas leituras do mundo, pois as práticas de letramento estão intimamente ligadas à construção, comunicação e negociação de significados e não se restringem a um só contexto, mas se diferenciam de acordo com as situações em que ocorrem.

Desse modo, passamos a avaliar em sintonia com as demandas da nova ordem que se estabelece, rompendo com os padrões avaliativos pautados no que Kalantzis et al (2003, p. 19) chamam de regurgitation of rigidly defined truths ${ }^{7}$.

\section{Considerações Finais}

O presente artigo objetivou mostrar fontes de insumo, capazes de levar a decisões a serem tomadas em sala de aula. Conforme discutido na introdução professores formadores podem consistentemente, trabalhar as questões relativas à avaliação durante a formação inicial e continuada do professor em formação.

Parece-nos oportuno enfatizar que o fundamento básico da avaliação não reside na lógica das hierarquias de excelência, mas na lógica das pedagogias diferenciadas, sobretudo na tentativa de explorar maneiras de organizar o ensino sem manter o pressuposto de uma relação específica entre ensino e aprendizagem, além de buscar maneiras de avaliar diferentes formas de aprendizagem. Tal exploração nos leva a propor que o ensino seja também sensível às emoções, as quais, como já discutimos, influenciam os processos cognitivos durante os julgamentos e processamento de inferências.

Neste artigo, buscamos problematizar determinadas concepções prototípicas, solidificadas historicamente e não permeáveis à dialogia com novas propostas conceituais e, ao mesmo tempo, discutir os desafios referentes aos letramentos na atualidade, sobretudo, de modo crítico (cf. MONTE MÓR, 2013), propondo práxis alternativas de avaliação com vistas

\footnotetext{
${ }^{7}$ No mundo animal, a prática de regurgitation, citada pelos autores (2003), é lugar comum para muitos pássaros que lançam para fora alimento consumido, em prol da alimentação de seus rebentos. A metáfora transplantada para o contexto avaliativo transmite a ideia do processo fixo e costumeiro de respostas corretas que devem ser "cuspidas" pelos alunos quando requisitados através de provas e testes.
} 
à formação de cidadãos éticos e solidários, propensos a melhor lidar com a diferença e a complexidade das sociedades digitais.

Espera-se que as categorias de análise aqui dispostas possam inspirar questionamentos e a ressignificação da avaliação da aprendizagem de Língua Inglesa no âmbito escolar em prol da obtenção de uma resposta à pergunta "como melhor avaliar as amplas habilidades e atributos requeridos pela nova ordem mundial?"

\section{Referências}

ALMEIDA FILHO, J. C. P. O professor de língua estrangeira em formação. Campinas, SP: Pontes, 1999.

Análise de abordagem como procedimento fundador de auto-conhecimento e mudança para o professor de língua estrangeira. In: ALMEIDA FILHO, J. C. P. O professor de língua estrangeira em formação. Campinas, SP: Pontes, 1999.

BÁRBARA, L. e RAMOS, Guerra (Org). Reflexão e Ações no Ensino-Aprendizagem de Linguas. Mercado de Letras. 2003.

BRASIL. Ministério de Educação e Cultura. PCN+ Ensino Médio: orientações educacionais complementares aos Parâmetros Curriculares Nacionais: Linguagens e Códigos e suas Tecnologias. Brasília: MEC/SEMTEC, 2002.

BRYDON. D. Local Needs, Global Contexts: Learning New Literacies. 2010. Trabalho apresentado no I Seminário Formação de Professores e Ensino de Língua Inglesa, SEFELI, São Cristóvão - SE, 2010.

CELANI, M. A. A. A Relevância da Linguística Aplicada na Formulação de uma Política Educacional Brasileira. In: FORTKAMO, M. B. M e TOMITCH, L.M.B. Aspectos da Linguística Aplicada - Estudos em homenagem ao Professor Hilário Inácio Bohn. Editora Insular, 2008.

CELANI, M. A. A \& COLLINS, H. Formação contínua de professores em contexto presencial e a distância: respondendo aos desafios. In: BÁRBARA, L. e RAMOS, Guerra (Org). Reflexão e Ações no Ensino-Aprendizagem de Línguas. Mercado de Letras. 2003.

COPE, B.; KALANTZIS, M. Multiliteracies: New Literacies, New Learning. Pedagogies: An International Journal, Vol. 4, p.164-195, 2009.

DUBOC, A. P. M. A avaliação da aprendizagem de língua inglesa segundo as novas teorias de letramento. Fragmentos, número 33, p. 263/277. Florianópolis/ jul - dez, 2007.

. Ensino e avaliação de línguas estrangeiras: tendências em curso. In: MULIK, K. B.; RETORTA, M. S. (Orgs.) Avaliação no ensino-aprendizado de línguas estrangeiras: diálogos, pesquisas e reflexões. Campinas, SP: Pontes, 2014. 
ELUF, C. A. Nova interface pedagógica: linguística de corpus+ multiletramentos na formação do professor de língua inglesa. São Paulo, 2010. 133f. Tese (doutorado em Letras Modernas) - Faculdade de Filosofia, Letras e Ciências Humanas, Universidade de São Paulo.

HALL, S. A identidade cultural na pós-modernidade. 11 ed. Rio de Janeiro: DP\&A, 2006.

KALANTZIS, M.; COPE, B.; HARVEY, A. Assessing Multiliteracies and the New Basics. Assessment in Education, vol. 10, $\mathrm{n}^{\mathrm{o}}$ 1, p. 15-26, 2003.

LANKSHEAR, C.; KNOBEL, M. New Literacies - changing knowledge and classroom learning. United Kingdom: Open University Press, 2003.

LUCKESI, C. C. Avaliação da aprendizagem escolar: estudos e proposições. - $10^{a}$ ed. - São Paulo: Cortez, 2000.

MCNAMARA, T. F. Modelling performance: opening Pandora's Box. In: MCNAMARA, T. F. Measuring second language performance. London: Longman, 1996.

MOITA LOPES, L. P. Fotografias da Linguística Aplicada no campo de línguas estrangeiras no Brasil. DELTA, São Paulo, v. 15, núm. esp., p. 419-435, 1999.

A nova ordem mundial, os parâmetros curriculares nacionais e o ensino de inglês no Brasil: a base intelectual para uma ação política. In: BÁRBARA, L. e RAMOS, Guerra (Org). Reflexão e Ações no Ensino-Aprendizagem de Línguas. Mercado de Letras. 2003.

Por uma linguística Aplicada Indisciplinar. São Paulo: Parábola, 2006.

Inglês e globalização em uma epistemologia de fronteira: ideologia lingüística para tempos híbridos. DELTA: Documentação de Estudos em Lingüística Teórica e Aplicada, v. 24, n. 2, p. 309-340, 2008.

MONTE MÓR, W. Crítica e letramentos críticos: reflexões preliminares. In: ROCHA, C. H.; MACIEL, R. F. (Orgs.) Língua estrangeira e formação cidadã: por entre discursos e práticas. Coleção: Novas perspectivas em linguística Aplicada. Vol. 33. Campinas, SP: Pontes Editores, 2013.

PERRENOUD, P. Avaliação: da excelência à regulação das aprendizagens - entre duas lógicas/ tradução Patrícia Chittoni Ramos. - Porto Alegre: Artmed, 1999.

PRABHU, N. S. Ensinar é, no máximo, esperar que o melhor aconteça. Horizontes de linguística aplicada: revista do Departamento de Línguas estrangeiras e Tradução da Universidade de Brasília - Ano 2, n. 01, p. 82-91, jul. 2003.

QUEVEDO-CAMARGO, G. Avaliação Docente em Língua inglesa: Uma Proposta de ação. Signum: Estud. Ling., Londrina, n. 14/1, 2011.

RAJAGOPALAN, K. Nova pragmática: fases e feições de um fazer. São Paulo: Parábola, 2010. 
ROCHA, C. H.; MACIEL, R. F. (Orgs.) Língua estrangeira e formação cidadã: por entre discursos e práticas. Coleção: Novas perspectivas em linguística Aplicada. Vol. 33. Campinas, SP: Pontes Editores, 2013.

ROJO, R.; MOURA, E. (orgs.). Multiletramentos na escola. São Paulo: Parábola Editorial, 2012.

SANTOS, M. Por uma outra globalização: do pensamento único à consciência universal. $6^{\mathrm{a}} \mathrm{ed}$. Rio de Janeiro: Record, 2001.

SCARAMUCCI, M. V. R. O professor avaliador: sobre a importância da avaliação na formação do professor de língua estrangeira. In: ROTTAVA, L.; SANTOS, S. S. (Orgs.). Ensino-aprendizagem de línguas: língua estrangeira. Ijuí: Editora da UNIJUI, p. 49-64, 2006.

SHOHAMY, E. G. The power of tests: a critical perspective on the uses of language tests. Pearson Education, 2001.

Recebido em: julho de 2014.

Aprovado em: janeiro de 2015. 